\title{
Garantías judiciales de la infancia en la prestación defectuosa de los servicios médicos*
}

\author{
Diana Constanza Tique Legro" \\ Claudia Lucía Barón Moreno
}

Recibido: 20 de marzo de 2020 • Aprobado: 10 de mayo de 2020

\section{Resumen}

El derecho a la salud corresponde a una garantía de reciente consagración en el derecho colombiano, puesto que es a partir de la Constitución Política del año 1991 que se acreditó de manera expresa como un derecho de segunda generación o de los denominados derechos sociales, económicos y culturales. Para el caso de los niños, se estableció en su artículo 44 de la Carta Magna que se trataría de un derecho fundamental, dándole total prevalencia y preferencia en la prestación de este tipo de servicios. Sin embargo, las deficiencias en la prestación del servicio de salud en Colombia, a pesar de las múltiples reformas, tuvo que ser cubierto por los administradores de justicia; jueces y magistrados de todo del país son quienes deben atener las tutelas como mecanismo constitucional de amparo directo para la protección de este derecho, y en cuanto a la reparación de los daños causados, a través de los procesos de reparación directa por fallas en el servicio médico. Frente a este último

\footnotetext{
* El presente artículo es producto del proyecto de investigación “Garantías judiciales para la protección de los niños, niñas y adolescentes en casos de responsabilidad del Estado colombiano por fallas del servicio médico-pediátrico en el periodo 2012-2019”, gestionado en el marco de la Maestría en Derecho Administrativo de la Universidad Libre, Bogotá, Colombia.

Citar como: Tique Legro, D. C. y Barón Moreno, C. L. (2020). Garantías judiciales de la infancia en la prestación defectuosa de los servicios médicos. Revista IUSTA, 53, 137-160. DOI: https://doi.org/10.15332/25005286.6274

** Abogada. Especialista en Derecho Constitucional y Derecho Administrativo, Probatorio y Derecho Penal de la Universidad Católica de Colombia. Estudiante de la Maestría en Derecho Administrativo de la Universidad Libre, seccional Bogotá. Correo electrónico: dicotile@hotmail.com. ORCID: 0000-0002-9022-4651.

-- Abogada de la Universidad la Gran Colombia. Especialista en Derecho Público de la Universidad la Republicana. Estudiante de la Maestría en Derecho Administrativo de la Universidad Libre, Seccional Bogotá. Correo electrónico: nanis772003@hotmail.com. orcid: 0000-0001-5851-6825.
} 
aspecto, se realiza un diagnóstico de las garantías judiciales que tienen los infantes para acceder a la jurisdicción pretendiendo un resarcimiento de perjuicios como consecuencia de una mala praxis. El presente artículo aborda la problemática existente en Colombia en torno a las fallas en el servicio médico-pediátrico partiendo del análisis de la jurisprudencia del Consejo de Estado y su evolución durante los últimos años, no obstante, esto se hace teniendo como referente si la misma se acompasa con los instrumentos internacionales que propenden por la protección de la niñez en todos sus órdenes y su acceso efectivo, no solo a los servicios de salud, sino también a las garantías en sede judicial.

Palabras clave: derecho a la salud, protección a la infancia, reparación de perjuicios, acceso a la administración de justicia, falla médica.

\title{
Judicial Guarantees of Children in the Defective Provision of Medical Services
}

\begin{abstract}
The right to health corresponds to a guarantee recently enshrined in Colombian law, in the Political Constitution of 1991, which expressly accredited it as a second generation right or belonging to so-called social, economic, and cultural rights. In the case of children, it was established in article 44 of the Magna Carta that this would be a fundamental right, giving full precedence and preference to the provision of this type of services. However, the shortcomings in the provision of health services in Colombia, despite the many reforms, had to be filled by the administrators of justice; judges and magistrates from all over the country are the ones who must enforce the guardianship, as a constitutional mechanism, of direct protection for the guaranteeing of this right, and also of reparation for the damages caused through the processes of direct reparation for failures in the medical service. With regard to the latter aspect, a diagnosis is made of the judicial guarantees that children have to gain access to courts of law in order to seek compensation for damages as a result of malpractice. This article addresses the problems existing in Colombia regarding failures in the medical-pediatric service based on the analysis of the jurisprudence of the Council of State and its evolution in recent years; however, this is done with reference to whether it is accompanied by international instruments that promote the protection of children in all their orders and their effective access, not only to health services, but also to guarantees in court.
\end{abstract}


Keywords: right to health, protection of children, reparation for damages, access to the administration of justice, medical failure.

\section{Garantias JUdiciais de CRIANÇAS NA PRESTAÇÃo DEFEITUOSA DE SERVIÇOS MÉDICOS}

\section{Resumo}

O direito à saúde corresponde a uma garantia de consagração recente na lei colombiana, uma vez que é a partir da Constituição Política de 1991 que foi expressamente reconhecido como um direito de segunda geração ou dos chamados "direitos sociais, econômicos e culturais". No caso das crianças, foi estabelecido em seu artigo $44 \mathrm{da}$ Magna Carta que ele seria um direito fundamental, conferindo plena prevalência e preferência na prestação desse tipo de serviços. No entanto, as deficiências na prestação de serviços de saúde na Colômbia, apesar de várias reformas, tiveram que ser cobertas pelos administradores da justiça; juízes e magistrados de todo o país são os que devem manter as tutelas como mecanismo constitucional de amparo direto para proteger esse direito e como reparação dos danos causados, através dos processos de reparação direta por falhas no serviço médico. Diante deste último aspecto, é feito um diagnóstico das garantias judiciais que as crianças têm para acessar a jurisdição, buscando indenização por danos em consequência de negligência. Este artigo aborda o problema existente na Colômbia em relação às falhas no serviço médico pediátrico com base na análise da jurisprudência do Conselho Estadual e sua evolução nos últimos anos. Isso é feito tomando como referência se ela está em consonância com os instrumentos internacionais que promovem a proteção da infância em todas as suas formas e seu efetivo acesso não apenas aos serviços de saúde, mas também a garantias judiciais.

Palavras-chave: direito à saúde, proteção infantil, reparação de danos, acesso à administração da justiça, falha médica. 


\section{Introducción}

En Colombia, la responsabilidad administrativa del Estado se ha extendido en la misma proporción en que determinada acción, omisión, hecho u operación administrativa de una entidad pública haya tenido injerencia. Es así como la jurisdicción de lo contencioso administrativo se ha caracterizado por contener un régimen normativo propio que responde a las particularidades individuales de los sujetos intervinientes en este tipo de litigios, siendo este el principal elemento diferenciador con las otras ramas del derecho.

Ello se justifica en la medida en que la carta fundamental de 1991 estableció que "el Estado es el garante de la satisfacción de las necesidades básicas para una vida digna (necesidades vitales) de todos los ciudadanos" (Delgado, 1995, p. 222). De esta manera, en el marco de un Estado social de derecho, la prestación de los servicios de salud se encuentra a su cargo, ya sea como prestador directo a través de entidades privadas. Es finalmente el Estado el responsable de asegurar estos servicios a toda la población colombiana.

La atribución de esta obligación impregna de contenido estatal todo el quehacer del sector salud en el panorama colombiano, "la responsabilidad del Estado en la provisión de servicios de salud pública es irrenunciable y es su deber intervenir en la provisión de servicios de atención médica con arreglo a principios de equidad" (Yamin, Ríos y Hurtado, 2002, p. 31).

Ahora bien, el derecho a la salud y el ejercicio de la actividad médica guardan una relación inescindible, pues esta última sirve de medio para garantizar la primera, en todo caso, la realidad ha mostrado que ello no siempre ocurre. "Una de las causas que se ha de tener en cuenta en los inadecuados resultados del proceso de la atención de salud está relacionada precisamente con el error médico, que en la actualidad constituye el problema de calidad más importante en todas las latitudes” (Ramos, 2011, p. 124).

La prestación anormal del servicio por parte de las entidades públicas es uno de los principales móviles por los que se acude a la administración de justicia para la reparación de los perjuicios ocasionados, entre los que también se encuentran afectados los infantes.

Desde esa perspectiva, entre las características que más llama la atención dentro de los procesos de reparación directa, se encuentra aquella que va íntimamente ligada al ejercicio oportuno de la acción. 
Hoy en día, las legislaciones que regulan los trámites ante la jurisdicción contenciosa administrativa han dado plena aplicabilidad a la institución jurídica de la caducidad de la acción, con la cual se busca limitar en el tiempo la interposición de demandas contra el Estado y resolver en un tiempo razonable todos aquellos conflictos en los que hace parte una entidad estatal (Garzón, 2013).

La situación esbozada deja entrever que, sin importar la condición del individuo reclamante, de no accionar en el tiempo oportuno, la consecuencia natural de dicha omisión es no poder acceder a la administración de justicia, aspecto que, en sí mismo, constituye de entrada en una limitación para el acceso a la administración de justicia, pues desconoce la capacidad de ejercicio de quienes por ley no la pueden ejercer, como es el caso de los niños, niñas y adolescentes, de ahí la importancia de concebir mecanismos que permitan flexibilizar la aplicación de la figura procesal de la caducidad.

\section{Contexto normativo de protección del derecho a la salud}

El derecho a la salud obtiene un reconocimiento de rango constitucional, a partir de la Constitución Política de 1991, en la que se establece de manera expresa como un derecho de segunda generación o de los denominados derechos sociales, económicos y culturales (Molina, 2016).

Con lo expuesto, no quiere significar que en periodos anteriores a 1990 la población colombiana no contará con servicios de salud, lo que sucede es que la ideología propia del Estado consistía básicamente en no inmiscuirse en temas que no fueran propiamente temas administrativos o de gobierno.

El reconocimiento de rango constitucional que le merece se acompasa a la nueva forma de Estado.

Así, el carácter social del Estado se explica en la obligación que tiene este en la prestación continua y eficiente de los servicios públicos, en la prioridad en el gasto social y en la intervención oportuna para crear las reglas necesarias para que las diferentes entidades e instituciones públicas o privadas puedan garantizar efectivamente la prestación de los servicios que sean requeridos. (Cárdenas, 2013, p. 202)

De esta manera, la salud era entendida más que como un derecho, una actividad de mercado. En palabras de Hernández (2000), “así, los servicios de salud 
constituían una organización social fragmentada con base en la dinámica del mercado o en la capacidad de pago de las personas, con injerencia limitada del Estado. Quien tenía los medios, pagaba. Quien no los tenía, pedía” (p. 124).

La nueva Constitución Política prometía ser más garantista y responsable en la prestación de los servicios de salud, ocupándose especialmente de los más vulnerables, es así como, para el caso de los niños, estableció en su artículo 44 que se trataría de un derecho fundamental de estos, dándole total prevalencia y preferencia en la prestación de este tipo de servicios (Guarín y Aldana, 2016).

La importancia de asegurar por vía constitucional este derecho para la infancia radica en la noción misma que la entraña; para Paz (2008), el concepto de salud "hasta hace muy pocos años, la enfermedad era el concepto a partir del cual se definía la salud, o más bien, los límites de ésta: la salud era la ausencia de enfermedad" (citado en Monnier, 1980, p. 38). No obstante, la acepción más acogida es la establecida por la Organización Mundial de la Salud, que "define la salud en su carta fundacional como el estado de completo bienestar físico, mental y social y no solamente la ausencia de enfermedades o afecciones" (oms, 1948).

El primer cimiento del reconocimiento al derecho a la salud que vino a efectuarse con la Constitución Política de 1991 vino a ser desarrollada con posterioridad a través del surgimiento de la Ley 100 de 1993, que efectuó toda una modificación del régimen del sistema de salud, hasta ese momento existente, prometiendo garantizar cobertura a todo habitante nacional. Para Tobo y Pardo (1998), "la seguridad social deja de ser privilegio de los trabajadores de algunas empresas y de las personas de altos ingresos para convertirse en un derecho de todos, busca darle a todos los habitantes de Colombia un plan integral de salud" (p. 64). Sería esta disposición normativa la que se encargaría de regular todo el tema relativo a la prestación de los servicios de salud, financiación del sistema, cobertura, y demás para el acceso a este derecho (Forero, 2014).

Sin embargo, y pese al intenso desarrollo constitucional y legislativo que se dio a los inicios de los años noventa, poco a poco la realidad mostró graves fallas en la estructura del sistema de salud. En relación con el derecho a la salud de los niños, el tema parecía ser más pacífico, pues la Constitución Política lo había caracterizado desde un principio como un derecho fundamental, por lo que era vidente su carácter prevalente y preferencial, en la atención de los servicios de salud, que fueran necesarios para el restablecimiento de su salud o la conservación de la vida (González, 2016). 
Aunque la situación parecía clara en ese escenario, para otros autores el derecho a la salud era un todo más complejo, y, en todo caso, el derecho a la salud seguía siendo un derecho social fundamental. En palabras de Arango (2005), "los derechos sociales fundamentales son derechos fundamentales, es decir, derechos subjetivos con un alto grado de importancia. Pero lo que distingue a los derechos sociales fundamentales de otros derechos fundamentales (...) es que son 'derechos de prestación en su sentido estrecho" (p. 37).

De esta manera, la tesis planteada por el autor consistía básicamente en que muy a pesar de existir derechos sociales, estos no eran considerados como fundamentales, por no aparecer expresamente así señalados en el articulado constitucional.

En todo caso, el tema de si la salud es un derecho fundamental autónomo o por conexidad quedó zanjado por la Corte Constitucional en Sentencia T-760 de 2008, al afirmar:

[...] el carácter fundamental de un derecho no se debe a que el texto constitucional lo diga expresamente, o a que ubique el artículo correspondiente dentro de un determinado capítulo $[\ldots]$ pues no pueden negarse como derechos aquellos que 'siendo inherentes a la persona humana', no estén enunciados en la Carta. [De manera que] La fundamentalidad del derecho a la salud exige que las autoridades de regulación adopten las determinaciones para protegerlo [...] y garantizar el goce efectivo del derecho por todos los usuarios del sistema de seguridad social en salud. (Sentencia T-760/2008)

A partir de esta decisión, se produjo una readecuación en la categorización del derecho a la salud, en razón a que pasó, del segundo plano en el que se encontraba, a tomar el protagonismo como derecho fundamental que se imponía. Pese a esto, autores como Gañán (2011) afirman:

Se puede decir que no existe aún una línea jurisprudencial unánime acerca de la naturaleza iusfundamental del derecho a la salud en la Corte Constitucional. [...]. En el mismo sentido pueden apreciarse recientes sentencias de la propia Corte Constitucional que han retomado el concepto de conexidad para determinar la fundamentalidad del derecho a la salud (p. 209).

Con todo, hoy por hoy, muchas de las dudas han sido despejadas, se reconoce el derecho a la salud como de carácter fundamental, no hay duda de su justiciabilidad 
a través de la acción de tutela, no como un derecho conexo, sino como un derecho autónomo e independiente de su interrelación con otras garantías (Ballesteros, 2015).

\section{Principales fallas del servicio médico-pediátrico que afectan el derecho a la salud de los niños en Colombia}

En Colombia, de manera concreta, no existe ninguna disposición normativa que regule lo relacionado a las fallas del servicio médico, en tanto dicha construcción conceptual se ha gestado, en otros escenarios, como en el doctrinario y la jurisprudencia de las altas cortes.

Sin embargo, mucho antes de la Constitución de 1991, se había dispuesto legislativamente la necesidad de garantizar una adecua prestación de los servicios de salud. Tal es el caso, de la Ley 23 de 1981, "Por lo cual se dictan Normas en Materia de Ética Médica”, disposición que se encargó de establecer el objeto de la medicina como profesión, señalando que su principal fin es cuidar la salud del hombre y propender por la prevención de las enfermedades, con respeto a la dignidad humana, y haciendo uso de los métodos científicos avalados por la ciencia médica.

Para autores como Ruiz (2004):

[...] solo la sociedad consumista y reivindicativa, celosamente defensor de los derechos individuales y, porque no, de los fundamentales, pudo sentar al banquillo, para pedir reparación jurídica y material, a los médicos que ocasionan un daño para el paciente en el desempeño de su profesión. (p. 197)

En los albores de la sociedad, el médico era considerado un dador de bienestar al paciente, lejos estaba planteada la posibilidad de llamarlo a juicio de responsabilidad, en aquellos casos en que no se obtenía este bienestar. Sin embargo, la realidad mostró que quienes ejercitan están profesión, muchas veces, por negligencia o desatención, agraviaban al paciente, por lo que prontamente fueron incluidos como sujetos jurídicamente responsables de los daños causados.

En efecto, así ocurrió en nuestra legislación el artículo 2341 del Código Civil, que consignó que quien ha cometido un delito o culpa que ha inferido daño a otro es obligado a la indemnización sin perjuicio de la pena principal que la ley imponga. 
En palabras de Cabarcas (2002), “puede entenderse por 'mal praxis', 'mal práctica' o 'mala práctica', la actuación imprudente o negligente del médico que ocasiona un daño en la salud del paciente y que incluye los errores médicos” (p. 34).

$\mathrm{Al}$ anterior concepto es a lo que se le ha denominado por parte de la doctrina como falla del servicio médico, acogida plenamente por la jurisprudencia del Consejo de Estado, y que suele referenciar a la anormalidad en la prestación de los servicios de salud.

La actividad médica se desarrolla a partir de un lenguaje universal que obedece principalmente a que su objeto de trabajo no es otro que el cuerpo humano, sin embargo, esa aparente simplicidad no hace menos compleja la labor médica, la cual de por sí está encaminada al mantenimiento de una buena salud de los individuos. Vera (2013) afirma que "el acto médico se refiere a lo que realiza el profesional de la medicina en el desempeño de su profesión frente al paciente (Ética Médica Individual) y a la sociedad (Ética Médica Social)" (p. 73).

Entre las definiciones que más se acogen en la comunidad académica, por integrar todas las características de lo que debe ser considerado como un acto médico, resalta lo expuesto por la Unión Europea de Médicos Especialista, como se cita en Heras (2003), quien la define como el "tratamiento, intervención o exámenes con fines diagnósticos, profilácticos, terapéuticos o de rehabilitación llevados a cabo por un médico o bajo su responsabilidad" (p. 578).

A partir de todo lo discurrido, puede afirmarse que el acto médico es el resultado mismo del ejercicio de la medicina, en el que intervienen diferentes actores con necesidades claramente diferenciadas, pero encaminadas hacia un mismo fin, que es ofrecer el restablecimiento de la salud.

De otra parte, es de destacar el surgimiento de una nueva disciplina hacia mediados de los años setenta, concebida como bioética, la cual impregnó a la ciencia médica con el objeto de humanizar el conocimiento utilizado desde esta área para evitar que sirviera como arma de destrucción del hombre (Guarín, 2015).

Cuando se habla de fallas en el servicio de salud o médicas, es necesario tener claridad sobre qué es el daño a la salud. Rozo (2002) expone que

Es el daño biológico consiste en aquellas situaciones de invalidez física, perdida de funcionalidad de un órgano, de perturbación, impotencia sexual, enfermedades nerviosas o psicomáticas, $[$ sic $]$ insomnio, trastornos mentales, y cualquier otra lesión permanente o no, de la persona víctima en cuanto entidad biológica. (p. 112) 
No podemos dejar de un lado que el daño debe ser cierto, personal, determinado (daño emergente) o indeterminado (lucro cesante) y anormal.

A su turno, autores como Sánchez, Camelo y Giraldo (2015) entienden la falla de la atención en salud, como:

Una deficiencia para realizar una acción prevista según lo programado o la utilización de un plan incorrecto, lo cual se puede manifestar mediante la ejecución de procesos incorrectos (falla de acción) o mediante la no ejecución de los procesos correctos (falla de omisión) en las fases de planeación o de ejecución. (p. 15)

En ese orden de ideas, puede afirmarse que la correlación entre los principios que erigen la actividad, más el cumplimiento de las reglas de la lex artis, generan una adecuada prestación del servicio médico, pero, por el contrario, cuando se desatienden los principios éticos médicos y se falta a las reglas de la lex artis, se produce una falla del servicio médico, lo cual indica que este funcionó mal, no funciono o funcionó de manera tardía.

Como lo índica Aldana (2018), "la falla del servicio corresponde a un desarrollo particular de la teoría del servicio público, surgida en el derecho francés en los años 20, se utilizó para explicar la existencia y funcionamiento de la organización estatal" (p. 7). De ahí que los mayores avances sobre los elementos configuradores de la existencia de fallas del servicio médico en salud se sirvan en mayor medida de los mismos configurados en las fallas para la prestación del servicio público.

\section{La responsabilidad del Estado colombiano en el marco de fallas médico-pediátricas que afectan el derecho a la salud de los niños}

En Colombia, la responsabilidad patrimonial del Estado se cimienta sobre la jurisprudencia, que en sus inicios comenzó a instituir la Corte Suprema de Justicia con fundamento en normas propias del Código Civil, especialmente las contempladas en los artículos 2347 y 2349, que hacen referencia a la responsabilidad por el hecho propio y de las personas a cargo, así como la establecida en el artículo 2356, relativa a la responsabilidad por negligencia.

De esta manera, la actuación de la administración era analizada bajo los mismos derroteros que cualquier particular, no obstante, hacia mediados de 1939 se comenzó 
a estructurar toda una tesis, que propendía por un sistema de responsabilidad autónomo para las entidades públicas, que se acompasara con la realidad, misión y visión de este tipo de entidades.

Es así como mediante una decisión del 30 de junio de 1962 con ponencia del magistrado Carlos Peláez, la Corte Suprema de Justicia realizó rectificación de doctrina frente a este tema y comenzó a sentar las bases para predicar una responsabilidad estatal desligada del Código Civil, en tanto verificó que la misma no puede servirse de los mismos fundamentos en que se responsabiliza a un particular, dado que las funciones que desarrollan las diferentes entidades del Estado se asimilan a la de las personas morales (sociedades y empresas) cuya responsabilidad se predica por la elección de sus dependientes, culpa in eligiendo, así como por la falta de vigilancia sobre estos, culpa in vigilando.

La gestación de una teoría del servicio público comenzó a abrirse paso, llegándose a consolidar finalmente con la expedición del Decreto 528 de 1964, "Por el cual se dictan normas sobre organización judicial y competencia, se desarrolla el artículo 217 de la Constitución, y se adoptan otras disposiciones”. A través de esta normativa, se traslada al Consejo de Estado el conocimiento de los asuntos, donde se encuentran involucradas entidades del servicio público.

Posteriormente, también se delineó de manera expresa con la expedición del Decreto 01 de 1984, tal y como lo refirió Bustamante (1998):

[...] la responsabilidad administrativa del Estado, la responsabilidad de los servidores públicos por daños que ocasione en ejercicio de sus funciones y que sean imputables a título de dolo o culpa grave y se consagró la llamada acumulación de responsabilidades que permite demandar conjunta o separadamente a la entidad pública y al funcionario. (p. 197)

Finalmente, con la Constitución Política de 1991, se estableció en su artículo 90 la denominada "cláusula general de responsabilidad del Estado", a partir del cual la jurisdicción especializada encabezada por el Consejo de Estado, tribunales administrativos y juzgados administrativos, comenzó a desarrollar toda una teoría acerca de la responsabilidad del Estado, regímenes de imputación y toda una gama de figuras jurídicas que son propias del servicio público.

Cuando de responsabilidad de las entidades estatales se trata, siempre se hace alusión a dos regímenes generales de imputación, por un lado, encontramos el 
régimen subjetivo al cual pertenece la falla del servicio de la administración, que se caracteriza por la culpa o negligencia del Estado en el desarrollo y cumplimiento de las funciones encomendadas por la constitución y la ley, y, por otro lado, el régimen de responsabilidad objetivo, el cual se caracteriza porque no hay una deficiente prestación del servicio, por el contrario, pese a que se cumplen con las funciones de manera normal aun así se causan daños antijurídicos.

La responsabilidad del Estado por la falla en la prestación del servicio médico corresponde por excelencia el título de imputación, al cual se acude cuando se presenta anormalidad en la prestación de los servicios de salud a cargo del Estado (Gallego, 2014).

En la falla probada del servicio, es necesario demostrar la irregularidad en el actuar público, es decir, la culpabilidad de la administración (Güechá, 2011), mientras que en la falla presunta dicha irregularidad se presume o se da por sentada, eximiendo al interesado de su acreditación.

La jurisdicción de lo contencioso administrativo, encabezada por el Consejo de Estado, desarrollo un régimen común de responsabilidad extracontractual del Estado por daños causados a terceros, basado en la idea de que es la administración quien debe responder por las fallas que se le imputan a sus agentes en el ejercicio cotidiano de la actividad pública, teniendo en cuenta que si la administración dentro de sus obligaciones no actuó cuando debía hacerlo, actuó pero de forma indebida o lo hizo bien pero tardíamente. (Correa, 2012, p. 36)

Sobre este aspecto conviene precisar que los elementos que la conforman son los mismos, en que se fundamenta la falla del servicio in extenso, solo que su análisis se circunscribe al campo de la medicina pediátrica, sin embargo, los abordaremos individualmente de cara al estudio que nos compete:

- Daño: esta acepción, de acuerdo con el diccionario de la Real Academia Española, es entendida como perjuicio o lesión, aunque también la contempla como el efecto lesivo de carácter patrimonial, físico o moral que deriva de la actuación de los poderes públicos.

- Culpa o falla de la administración: corresponde al elemento característico de la falla del servicio, que se caracteriza por un actuar negligente, descuidado o desatento de los agentes del Estado, que generan daños a los administrados. Se asocia a la inobservancia de los procedimientos legales o de la 
especialidad a la que pertenecen, causado una irregularidad en la prestación de los servicios.

En responsabilidad médica, son tantas las posibles formas de culpa como la imaginación logre diseñar. Puede ocurrir desde la tardanza en la atención hasta la falta de cuidados postoperatorios, pasando por diagnósticos errados, impericia en el acto médico, el olvido de elementos quirúrgicos dentro del paciente y, en general, cualquier incumplimiento de los deberes principales y secundarios que van implícitos en el juramento hipocrático (Acosta, 2010, p. 5).

- Nexo de causalidad: la relación de causalidad entre el daño antijurídico y el obrar culposo del agente exige que el uno sea la consecución del otro, pues de no ser así el daño no resultaría ser atribuible al Estado, sino a una causa externa, generando con ello un eximente de responsabilidad.

La importancia de este elemento en materia de responsabilidad médica converge en el tema de prueba, en tanto en diversas ocasiones no es posible determinar con claridad si en efecto el daño puede ser atribuido al actuar médico.

Para autores como Bueres (1979),

El contacto físico entre un profesional y un paciente que experimenta daños, no permite indefectiblemente imputar estos daños al susodicho profesional, pues las pruebas aportadas al proceso, con suma frecuencia, suscitan dudas acerca de si el obrar médico fue en verdad el que ocasionó los perjuicios. (pp. 312-313)

\section{Deficiencias y fortalezas de la responsabilidad del Estado por fallas del servicio médico pediátrico}

La atención en salud para los niños, niñas y adolescentes en el territorial nacional, por parte de hospitales públicos, ha llamado la atención en razón de las diferentes demandas que se han promovido en contra de estas entidades, como consecuencia de factores atribuibles a mala praxis, insuficiencia de medios de atención, diagnósticos erróneos, inexistencia de consentimiento previo, entre otros, que han generado que muchos de los asuntos que se radican ante los jueces contencioso administrativos correspondan a medios de control de reparación directa, en procura de obtener un reconocimiento y resarcimiento de perjuicios. 
En todos estos casos, las víctimas directas e indirectas del daño son menores de edad, quienes han sufrido en carne propia las secuelas que genera una deficiente atención médica, siendo esta la principal población de la cual se ocupa la presente investigación.

De ahí la radical importancia de entrar a identificar cuáles son las fortalezas y deficiencias que actualmente tiene el Estado frente a esta temática, pues a la hora de hablar de responsabilidad estatal por las fallas del servicio médico pediátrico son muchas las circunstancias que en pro y en contra se hallan, viéndose los niños, niñas y adolescentes avocados a diferentes obstáculos, que no se acompasan con la protección supraconstitucional que los resguarda.

Como fortalezas por destacar, se señalan las siguientes:

\section{- Adopción de políticas en materia de prevención del daño antijurídico por parte de las entidades estatales}

Tras el aumento de litigiosidad en el que se han visto involucradas diferentes entidades estatales, entre las que se encuentran aquellas provenientes de la actividad médica por parte de hospitales o centros de atención públicos, se destaca que a partir del año 2011 con la expedición de la Ley 1444 de esa misma anualidad, la creación de la denominada Agencia Nacional de Defensa Jurídica del Estado, entidad descentralizada del orden nacional, cuyo propósito principal es el establecimiento de políticas de prevención de conductas antijurídicas, respecto de las cuales el Estado ha sido repetitivamente condenado.

Es la primera vez que se instituye un organismo que propende por defender al Estado jurídicamente al interior de todos aquellos asuntos en que se encuentra comprometida su responsabilidad, la cual, más allá de su representación en defensa de los intereses patrimoniales de la Nación, destaca la política de prevención para que hechos respecto de los cuales se le ha condenado, no sean objeto de repetición. "La prevención del daño antijurídico se refiere a evitar tanto situaciones de funcionamiento anormal como normal para las entidades estatales, que puedan generar un daño antijurídico para el particular que derive en una demanda contra el Estado" (Salas, 2015, p. 41).

Sin duda, una política de prevención del daño antijurídico que comprometa a cada una de las entidades que conforman el sector público, en especial, respecto a la atención médica en salud de los niños, niñas y adolescente, exige el cumplimiento de formulación, evaluación y socialización de los hallazgos en que 
se han divisado dichas falencias de orden administrativo, médico, ocupacional, con el fin de que sirvan como experiencia a otros estamentos en no en incurrir en los mismos errores.

En esa medida, Agencia Nacional de Defensa Jurídica del Estado tiene tres frentes que van desde el Sistema Único de Información Litigiosa, la Defensa Jurídica de los Intereses Litigiosos del Estado, hasta la formulación de políticas y estrategias para la prevención del daño antijurídico. (Urrego, 2015, p. 64)

En el caso de los niños, extremar los cuidados a la hora de su atención en urgencias, diagnósticos tempranos sobre la realidad de las patologías que los aquejan, mayor atención a las condiciones de salubridad, es el principal apremio que se le puede brindar a un paciente, pues ninguna compensación económica sustituirá el perjuicio psicológico, moral o en la salud que le haya sido causado.

\section{- Uso de mecanismos alternativos de solución de conflictos: conciliación prejudicial y judicial}

Con las leyes 446 de 1998 y Ley 640 de 2001, se introdujo la aplicación de mecanismos alternativos de solución de conflictos, cuyo propósito principal es la descongestión de los despachos judiciales; sin embargo, la jurisprudencia constitucional, desde un punto de vista más jurídico, la ha definido como "institución en virtud de la cual se persigue un interés público, mediante la solución negociada de un conflicto jurídico entre partes, con la intervención de un funcionario estatal perteneciente a la rama judicial o a la administrativa" (Sentencia C-160/1999, A. Barrera).

Por mucho tiempo, la administración en todos sus órdenes desusó este mecanismo y, pese a contar con suficientes elementos que le permitieran saber de antemano la condena a la que se vería avocada, insistía en esperar hasta los fallos de segunda instancia para posteriormente alargar el pago de condenas, por lo tanto, eran poco o nada las conciliaciones prejudiciales que se llevan a cabo por falta de ánimo o propuesta conciliatoria de la entidad pública.

En la mentalidad de muchos servidores públicos existe la creencia según la cual es mejor esperar una sentencia judicial, que conciliar, para así no comprometer el erario a su cargo y disposición ni correr riesgos políticos. Con esta postura no se educa a la sociedad, que tiene que partir de un principio elemental para la convivencia. (Dussan, 2009, p. 231) 
Sin embargo, a partir del año 2011 y con ocasión a la creación de la Agencia Nacional de Defensa Jurídica del Estado, como una de las entidades, integrantes de los Comité de Conciliación de las entidades del orden nacional, con voz y voto en estas, se determinó la procedencia del cambio de política y la necesidad de plantear propuestas conciliatorias que tuvieran un menor impacto en los recursos de las entidades.

En ese sentido, González (2010), afirma:

En virtud de la consagración de la conciliación extrajudicial como requisito de procedibilidad los Comités de Conciliación se han convertido en la máxima instancia administrativa al interior de cada entidad, toda vez que al decidir cada caso concreto, como les corresponde, son depositarios de la importante opción jurídica de conciliar. (p. 70)

En materia de responsabilidad médica, cuanto las víctimas del daño son adultos o menores de edad, la implementación de esta política resulta totalmente beneficiosa para los reclamantes, pues, sin duda, es una forma de satisfacer prontamente los daños que les han sido ocasionados sin tener que someterse a los tiempos procesales propios de la jurisdicción contenciosa administrativa.

En lo que respecta a las deficiencias, destacamos las siguientes:

- Ausencia de reparación no pecuniaria de perjuicios en favor de la infancia, afectada por fallas del servicio médico-pediátrico

En materia de reparación de daños, la regla general es que estos se resarcen materialmente a través del pago en dinero, y ese es precisamente el parámetro que ha guiado al Consejo de Estado como medida resarcitoria, en los procesos de reparación. Para Escobar, Benítez y Cárdenas (2011), "esta primera parte de la jurisprudencia del Consejo de Estado va del año 1992 a 2008 y se caracteriza especialmente porque sigue el patrón clásico del derecho administrativo, de acuerdo con el cual las reparaciones son eminentemente económicas" (p. 174).

No obstante y como se ha podido avizorar en diferentes decisiones del Consejo de Estado cuando se tratan de asuntos en que se discute la responsabilidad del Estado, por hechos que configuran delitos de lesa humana, se ha optado en estos asuntos por la posibilidad de adoptar medidas de reparación no pecuniarias por afectación relevante a bienes o derechos constitucionalmente y convencionalmente 
amparados, de esta manera se garantiza una satisfacción plena de los perjuicios que le han sido causados (Llano, 2013).

Es decir que, a partir de una interpretación armónica y sistemática de la norma, tanto de la interna como de las contenidas en disposiciones convencionales, y en aras de garantizar una reparación plena de perjuicios, además del reconocimiento pecuniario, se adoptan otras decisiones encaminadas a brindar una reparación plena a las víctimas, tales como las excusas y el perdón público, compromisos de no repetición, entre otros.

A la fecha, y pese a que bajo ese mismo criterio es posible implementar medidas no pecuarias en el resarcimiento de perjuicios a favor de los niños, con ocasión de fallas del servicio médico, pues existen normativas constitucionales y legales del orden interno, así como disposiciones del orden internacional que propenden por la extrema y reforzada protección a los derechos de la infancia, lo cierto es que poco o nada se implementan en asuntos de responsabilidad estatal por los hechos ya referenciados.

Escobar, Benítez y Cárdenas (2011), sostienen:

[...] sentencias del Consejo de Estado incorporan la más de las veces, nuevas formas de reparación que trascienden el tema económico, con lo cual, esa Corporación abandona parcialmente su jurisprudencia administrativista clásica y sigue más de cerca los estándares de la Corte Interamericana. Además de lo anterior, en líneas generales, otra característica de este nuevo tramo jurisprudencial es la ausencia de pronunciamientos "domésticos" previos, a las sentencias de la Corte Interamericana en las que se condena al Estado. En ese orden de ideas, los estándares sobre reparación vertidos en sentencias de la Corte Interamericana, en las cuales se ordena al Estado Colombiano reparar a las víctimas, se proyectan en la jurisprudencia del Consejo de Estado posterior a esos pronunciamientos y que tratan casos similares a los ya decididos por la Corte Interamericana. (p. 176)

Sin duda, las afectaciones físicas y psicológicas que sufren los niños como resultado de una mala praxis, de un mal diagnóstico, pese a ser compensadas en dinero, con el reconocimiento de indemnizaciones de acuerdo con los lineamientos dispuestos por el órgano de cierre, lejos están de mitigar el verdadero daño que les ha sido causado, pues muchas veces las sumas dinerarias que le son reconocidas no son aprovechadas directamente por el menor, de ahí la necesidad de la implementación 
de medidas de reparación no pecuniarias, como tratamientos psicológicos, tratamientos terapéuticos y de rehabilitación.

- Ausencia de posición uniforme de la jurisdicción contenciosa administrativa para garantizar el acceso a la administración de justicia de los menores de edad en la reclamación de perjuicios por fallas médicas

Es de conocimiento que el instituto de la caducidad constituye un presupuesto de acción, en todas aquellas demandas respecto de las cuales se pretende un reconocimiento de perjuicios a cargo del Estado. Y es que a través de esta figura se le impuso al ciudadano una carga para que ejerciera sus derechos dentro de los términos señalados por las leyes procesales.

Hoy en día, sentencias judiciales del Estado de Argentina se han adelantado a una nueva interpretación de esta figura de cara al reconocimiento de derechos de los infantes. Así se dio a conocer en la reciente decisión dentro del caso n. ${ }^{\circ}$ 126860:

La cuestión radica en establecer si cuando es actor una persona menor de edad, ante la inoficiosidad de la actividad del padre y/o el letrado que este eligió, el juez debe dar traslado al Asesor de Menores previo a resolver, para que éste pueda asumir la representación principal que le atribuye el ordenamiento. Consideramos que ante la grave consecuencia que la caducidad de instancia implica, ya que conlleva la pérdida del derecho del niño, corresponde notificar previa o coetáneamente al Asesor de Menores, pues sin este aviso no podrá cumplir el rol que le otorga el sistema jurídico para la protección de los derechos: suplir la defectuosa defensa hecha por los padres. (p. 3)

La jurisprudencia de esa alta corporación para el año 2006, refiriéndose a la caducidad en las acciones de reparación directa, determinó que esta obedecía a una interpretación exegética y gramatical de la norma, según la cual todo ciudadano que pretendiera acudir al Estado en busca de la reparación de perjuicios debía acudir en un plazo de dos años, siguientes al acaecimiento del hecho, omisión u operación administrativa, con el fin de hacer valer su derecho, so pena de que, de no hacerlo, el Estado no pudiere garantizarle el reconocimiento de los perjuicios reclamados.

Este tipo de postura no diferenciaba si quien accionaba en busca de dicha reparación era un niño, niña o adolescente, ni mucho menos se ahondaba en las razones por las cuales la persona no había acudido en término al ejercicio de su 
acción, esto basado en la convicción legal, que al ser un plazo previamente definido por el legislador solo le quedaba al juez efectuar la simple verificación numérica. Pese a ser la posición dominante y pacífica al interior de la sección tercera del Consejo de Estado, se empieza a gestar un nuevo enfoque que lleva a pensar en la necesidad de adecuar estos parámetros normativos no solo a las realidades sociales de los infantes, sino también a los compromisos internacionales que ha adquirido el Estado, en el denominado bloque de constitucionalidad, concretamente en la protección de la niñez.

Esta nueva postura se sentó en un primer momento a través de acciones de tutela, en el que se reclamaba por parte de los sujetos procesales accionantes, entre ellos niños, que se amparara su derecho fundamental de acceder a la administración de justicia. La acción de tutela se convirtió, por excelencia, en la única vía, a fin de garantizar a los infantes la posibilidad de discutir la responsabilidad del Estado, en hechos u omisiones atribuibles a una deficiente prestación del servicio médico y poder obtener un reconocimiento por esos perjuicios causados.

Sin embargo, hasta el día de hoy, son muchos los casos en los jueces de la jurisdicción contenciosa administrativa que no acogen plenamente la nueva postura del órgano de cierre por vía de tutela, y aunque el Consejo de Estado en diferentes autos ha exhortado a estas autoridades judiciales a efectuar un verdadero control de convencionalidad difuso en los asuntos que son sometidos a su consideración, en especial cuando se reclaman en perjuicios a favor de niños, con ocasión de fallas del servicio médico, esta en no muy pocas ocasiones es desatendida.

\section{Conclusiones}

En Colombia, la responsabilidad del Estado por fallas del servicio médico pediátrico está arraigado a una política de reparación del daño antijurídico, más no a su prevención, debido en gran parte a la falta de estrategias públicas en dicho sentido, lo cual aunado a la deficiente prestación de los servicios de salud en el territorio nacional, por la ausencia de una adecuada infraestructura física, tecnológica y de talento humano, ha provocado una posición amañada en este sentido, limitándose al reconocimiento y pago de obligaciones que por este aspecto resulte condenada.

En este trabajo de investigación se analizó una población en especial, como son los infantes que han sido víctimas de la deficiente prestación del servicio de salud en Colombia, no solo producto de una mala praxis en instituciones hospitalarias 
públicas, sino también por las ineficientes e inadecuada infraestructura del sistema de salud, quienes a la hora de pretender ante las autoridades judiciales una reparación de perjuicios a cargo del Estado, por el daño antijurídico que les han sido causado, han encontrado obstáculos de acceso a la administración y efectividad plena en el reconocimiento de sus derechos sustanciales, situación que va en contravía de lo preceptuado en tratados y convenciones internacionales en favor de la niñez.

Aunque el objeto de la actividad médica es la mejoría y recuperación del paciente, la práctica ha demostrado que en el ejercicio de esta profesión son comunes los errores del personal médico, siendo muchos de los afectados los niños, niñas y adolescentes; en otras ocasiones, también se ha vislumbrado que la anormalidad en la prestación de estos servicios es atribuible a la propia organización del sistema y a la poca cobertura de medios e infraestructura a cargo del Estado.

Estos hechos son lo que motivan la interposición de demandas en contra del Estado, en las denominada fallas del servicio médico, de ahí la necesidad de identificar las garantías que se ofrecen al interior de estos procesos a los niños, niñas y adolescentes, que acuden en sede jurisdiccional para la reparación de los perjuicios.

Desde este escenario, encontramos que en el ámbito del derecho público y de lo contencioso administrativo, se exige como presupuesto inexorable que no haya operado el fenómeno jurídico procesal de la caducidad, siendo este un elemento que debe ser analizado y declarado de manera oficiosa por el juez al momento de admitir la demanda.

Este corresponde a una de las primeras limitaciones, que deben superar los infantes para acceder a la jurisdicción, y es que, en la rigurosidad de esta figura, no existe convención, suspensión, interrupción, que pueda escapar de su estricta aplicación, ni siquiera condiciones particulares de los sujetos intervinientes pueden ser consideradas para menguar su aplicación. No obstante, sobre este último punto llama la atención en el presente trabajo de investigación que, durante los últimos años, se abrió el paso a una excepción a dicha regla general, y que obedece a la existencia de convenios internacionales que propenden por la protección de sujetos especiales.

A través de acciones de tutela se viene a garantizar el acceso efectivo a la administración de justicia, posición asumida por las altas cortes tanto de la jurisdicción constitucional como de la jurisdicción contenciosa administrativa, siendo este hoy en día la principal vía que garantiza la protección a ese derecho fundamental de los niños. 
Este panorama, aunque refleja un gran avance en el reconocimiento efectivo de derechos a favor de la infancia, no lo es del todo garantista, en primer lugar, porque muchos despachos judiciales que integran la jurisdicción contenciosa desconocen o pasan por alto la aplicación de dichas decisiones, generando que las demandas sean rechazadas y obligando a que el usuario de justicia deba acudir a mecanismos constitucionales como la acción de tutela, cuyos efectos son inter-partes y solo beneficiarían a quienes acuden a ella, generado un tema de desigualdad para quienes deciden no hacerlo.

En pocas palabras, aunque exista una garantía constitucional, como lo es la tutela, es indispensable que se acoja por parte de los jueces de la jurisdicción contenciosa, cuando son víctimas los infantes en daños antijurídicos por fallas del servicio médico atribuibles al Estado, una ampliación de la interpretación normativa tanto nacional como supranacional, en torno a las garantías de protección judicial de que goza la niñez. La cual incluso, en otras ramas del derecho, proscribe cualquier aplicación de figuras, como la prescripción o caducidad de sus derechos, por lo tanto, no sería descabellado pretender que la posibilidad de accionar para el reconocimiento de dichos perjuicios se amplíe para el infante hasta el momento en que cumpla su mayoría de edad, pues es el momento a partir del cual ejercen de manera propia todos sus derechos.

Por ello, la invitación al juez contencioso administrativo, para que en ejercicio de su función judicial y en aquellos asuntos, donde reclamen perjuicios niños, niñas y adolescentes víctimas de fallas del servicio médico, se adopten criterios garantistas en virtud del control de convencionalidad difuso que deben efectuar todas las autoridades judiciales al resolver los asuntos sometidos a su cargo.

En este caso, dar efectividad a los derechos de los infantes se traduce en la inaplicación de aquellos preceptos normativos que limitan el ejercicio del derecho, tal y como ocurre con el fenómeno de la caducidad del medio de control; hacerlo motu proprio, sin la necesidad de acudir a acciones extraordinarias, como la acción de tutela, optimiza el reconocimiento de derechos, pues no está sujeta a quien acuda a no a la protección de un derecho fundamental, como el acceso a la administración de justicia. 


\section{Referencias}

Acosta Madiedo, C. D. (2010). Responsabilidad médica: elementos, naturaleza y carga de la prueba. Revista de Derecho Privado, 43, 3-26. Universidad de los Andes.

Arango Rivadeneira, R. (2005). El concepto de derechos sociales fundamentales. (1. ${ }^{\mathrm{a}} \mathrm{ed}$. en español). Bogotá D. C., Colombia: Legis.

Ballesteros, C. (2015). La mujer y el ejercicio efectivo del poder en Colombia, una cuestión de Derechos Humanos. Revista Verba Iuris, 33, 61-76. Recuperado el 8 de mayo de 2018 de https://revistas.unilibre.edu.co/index.php/verbaiuris/article/view/27/24

Beauchamp, T. y Childress, J. (1999). Principios de ética biomédica. Barcelona, España: Editorial Masson.

Becerra Ramírez, J. de J. (s.f.). Los instrumentos internacionales de derechos fundamentales y su aplicación en el ámbito constitucional mexicano. Tesis doctoral. Universidad Carlos III de Madrid. Getafe, España.

Bueres, A. J. (1979). Responsabilidad civil de los médicos. Argentina: Hammurabi.

Bustamante Ledesma, Á. (1998). Evolución de la teoría. Responsabilidad extracontractual del Estado. Bogotá D. C., Colombia: Grupo Editorial Leyer.

Cabarcas, B. y Gelisbeth, H. (2002). La responsabilidad civil médica en nuestra legislación colombiana. Barraquilla, Colombia: Corporación Universitaria de la Costa.

Cárdenas, R. E. (2013). Alcances del derecho a la salud en Colombia: una revisión constitucional, legal y jurisprudencial. Revista de Derecho, 40, 198-225.

Corte Constitucional de Colombia. Sentencia T-760/2008. [M.P. Manuel José Cepeda Espinosa; julio 31 de 2008].

Correa Vargas, R. (2012). Análisis sistemático de la teoría de la responsabilidad. Bogotá D. C., Colombia: Leyer.

Delgado Ocando, J. M. (1991). Algunas reflexiones sobre el Estado social de derecho. Maracaibo, Venezuela: Instituto de Filosofía del Derecho. Facultad de Ciencias Jurídicas y Políticas de Luz.

Escobar Martínez, L. M., Benítez Rojas, V. F. y Cárdenas Poveda, M. (2011). La influencia de los estándares interamericanos de reparación en la jurisprudencia del Consejo de Estado Colombiano. Centro de Estudios Constitucionales de Chile, Universidad de Talca, 2, 165-190. 
Forero, J. (2014). El valor superior de la justicia en la Unión Europea. Especial referencia al Estado constitucional social y democrático de derecho español. Revista Verba Iuris, 31, 91-114. Recuperado el 5 de junio de 2018 de https://revistas.unilibre.edu.co/index.php/ verbaiuris/article/view/59/53

Gallego, J. (2014). Paradoja y complejidad de los derechos humanos en la sociedad moderna. Sentido y comunicación. Revista IUSTA, 40, 143-165.

Garzón, E. (2013). Globalización del derecho, fetichismo legal el velo de los derechos humanos. Revista Verba Iuris, 30, 56-78.

Gañán Ruiz, J. L. (2010). Los muertos de la Ley 100: prevalencia de la libertad económica sobro el derecho fundamental a la salud: una razón de su ineficacia. Caso del plan obligatorio de salud del régimen contributivo. (Tesis doctoral). Recuperado de http://bibliotecadigital.udea.edu.co/bitstream/10495/1437/1/JAIME\%20LE\%C3\%93N\%20 GA\%C3\%91\%C3\%81N\%20RUIZ.pdf

González, O. (2016). La omisión legislativa como hecho generador de la responsabilidad patrimonial del Estado. Revista Verba Iuris, 35, 41-63. Recuperado el 8 de marzo de 2018 de https://revistas.unilibre.edu.co/index.php/verbaiuris/article/view/5/2

Guarín, E. A. y Aldana, J. (2016). Estado jurisdiccional y bien común. Revista Verba Iuris, 11(36), 13-26.

Guarín Ramírez, E. A. (2015). Una aproximación filosófico-jurídica al sentido de la expresión. "Realización efectiva de los derechos". Revista Verba Iuris, 34, 147-159. Recuperado el 8 de mayo de 2018 de https://revistas.unilibre.edu.co/index.php/verbaiuris/article/ view/16/14

Güechá Medina, C. N. (2011). La falla en el servicio: una imputación tradicional de responsabilidad de responsabilidad del Estado. Prolegómenos. Derechos y Valores, XV, 95-109.

Heras García, M. Á. de las. (2003). Estatuto ético-jurídico de la profesión médica. (Tesis de doctorado). Universidad de Alicante. San Vicente del Raspeing. Alicante, España.

Hernández Álvarez, M. (2000). El derecho a la salud en Colombia: obstáculos estructurales para su realización. Revista de Salud Pública, 2(2), 121-144.

Llano, J. (2013). Prácticas jurídicas locales desde los actores del conflicto armado en Colombia. Revista IUSTA, 39(2), 257-287.

Molina González, Y. (2016). Derecho penal del enemigo y dignidad humana. Revista Verba Iuris, 11(36), 135-146. 
Monnier, J., Deschamps J. P., Fabry, J., Manciaux, M., Raimbault, A.M., Berthet, W., Roussel., A., Senault, R. (1980). Santé Publique, Santé de la Communauté. Villeurbanne, Francia.

Organización Mundial de la Salud (1948). Carta Fundacional de la Organización Mundial de la Salud. Ginebra.

Paz, L. B. (2008). Entre lo ideal y las realidades: la fisioterapia en la atención primaria domiciliaria. (Tesis de doctorado). Universitat de les Illes Balears. Palma de Mallorca. España.

Ramos Domínguez, B. N. (2011). Control de calidad de la atención de salud. (2.a ed.). La Habana, Cuba: Ciencias Médicas.

Rozo-Gutiérrez, N. y Vargas Trujillo, Z. (2018). Análisis de la Política Pública de Infancia y Adolescencia, 2011-2021, en Bogotá, D. C., Colombia. Desafíos, 30(2), 279-314. DoI: http://dx.doi.org/10.12804/revistas.urosario.edu.co/desafios/a.5325

Ruiz, W. (2004). La responsabilidad médica en Colombia. Critero Jurídico, 1(4). Recuperado a partir de https://revistas.javerianacali.edu.co/index.php/criteriojuridico/article/ view/232

Salas Varela, C. (2015). La Agencia Nacional de Defensa Jurídica del Estado y sus lineamientos en materia de responsabilidad objetiva: la privación injusta de la libertad y los accidentes de tránsito en vehiculos oficiales. (Tesis de Maestría). Facultad de Jurisprudencia. Universidad del Rosario. Bogotá D. C., Colombia.

Sánchez Cote, D. B., Camelo Barreto, J. A. y Giraldo Luna, C. M. (Julio de 2015). Prevalencia de eventos adversos en el Programa de Atención Domiciliaria 2014-2015. (Tesis de Maestría). Fundación Universitaria del Área Andina. Bogotá D. C., Colombia.

Tobo Vargas, N. y Pardo Torres, M. (1998). Aplicabilidad de la Ley 100 de 1993 en el cuidado de la familia: en una institución de carácter estatal en la ciudad de Bogotá. Avances en Enfermería, XVI(1-2), 61-70. Recuperado de https://revistas.unal.edu.co/ index.php/avenferm/article/view/16382/17309

Urrego Estrada, G. A. (2015). La defensa jurídica y patrimonial del Estado Colombiano: un reto institucional en el marco de la gubernamentalidad. Ánfora, 22(38), 61-23.

Vera, Ó. C. (2013). Aspectos éticos y legales del acto médico. Revista Médica la Paz, 19(2). Disponible en: http://www.scielo.org.bo/scielo.php?script=sci_arttext\&pid=S1726895 $82013000200010 \& \operatorname{lng}=\mathrm{es} \& n r m=i s o>$. ISSN 1726-8958.

Yamin, A., Ríos, M. y Hurtado, R. (2002). Derechos humanos y salud: vinculando dos perspectivas. Lima-Perú: Obtenido de http://www.inppares.org/sites/default/files/ Derechos\%20Humanos\%20y\%20S alud.pdf 